Title : The Pronunciation of Hong Kong English

Authors/Affiliation/email:

David Deterding

Universiti Brunei Darussalam

dhdeter@gmail.com

Jennie Wong

Hong Kong Institute of Education

jennie@ied.edu.hk

Andy Kirkpatrick

Hong Kong Institute of Education

akirkpat@ied.edu.hk 


\section{The Pronunciation of Hong Kong English}

\section{Introduction}

For many years, there has been plenty of interest in charting the development of the variety of English found in Hong Kong, and the fact that it is now often called "Hong Kong English" (Schneider 2007: 50) reflects its emergent status as an established variety of English, indicating a shift from the early eighties when Luke and Richards (1982) insisted that it lacked an independent identity and should therefore be referred to as "English in Hong Kong". However, despite all the recent attention focusing on this variety, surprisingly little work has been done to provide a wide-ranging description of its pronunciation based on the analysis of a substantial corpus of conversational data.

Luke and Richards (1982) offer a list of pronunciation features as well as the transcription of a few sentences from a 'mid-proficiency' speaker in the appendix of their paper, and Bolton and Kwok (1990, summarised in Bolton 2003: 206-9) give us an outline of the main phonetic features as well as the phonetic transcript of a short sample text spoken by a first-year university student. However, although these two papers offer a valuable start, neither include any quantitative results, either for the frequency of occurrence of the features that are listed or for acoustic measurements such as those that indicate the quality of vowels. 
Peng and Setter (2000) analyse in some detail the alternation between the occurrence and absence of final consonants such as [t] and [d] under certain morphological conditions, but this work is restricted to the production of citation words by two selected speakers. And Stibbard (2004) includes some useful data from recordings of seventeen undergraduates which adds to our knowledge about the pronunciation of Hong Kong English (even though his paper is written within a prescriptive framework that is at odds with the descriptive approach adopted here).

For quantitative studies of Hong Kong English, Hung (2000) presents some measurements of the monophthongs and diphthongs based on recordings of citation words by fifteen undergraduates at Hong Kong Baptist University. While this work gives us a solid foundation for considering vowel quality, we have little information about how the sounds would actually occur in connected speech. And in one paper that includes detailed frequency counts, Wong and Setter (2002) offer a careful analysis of the possible conflation of [n] and [l] in syllable-initial position based on a corpus of communicative data from seventeen undergraduates at Hong Kong Polytechnic University. However, this last investigation is restricted to just one small part of the sound system of Hong Kong English.

The current paper provides measurements and frequency counts of the features of Hong Kong English based on interviews with fifteen students at the Hong Kong 
Institute of Education. It also compares the data with other Englishes found in the region, particularly the Englishes of Singapore (Deterding 2003, 2007b), Mainland China (Deterding 2006), and the ten South-East Asian countries that belong to the ASEAN group of nations (Brunei, Cambodia, Indonesia, Laos, Malaysia, Myanmar, the Philippines, Singapore, Thailand and Vietnam) (Deterding and Kirkpatrick 2006). While in theory it is important to attempt to describe the phonology of each language variety on its own terms without reference to external varieties (Mohanan 1992), at the same time it can be valuable to compare the development Hong Kong English with other Englishes found in the region, to try to establish the degree to which the English spoken in the territory is unique or is participating in an emergent regional English lingua franca (Kirkpatrick 2007b). By mostly drawing comparisons with other new Englishes rather than inner-circle varieties such as those of Britain and North America, we avoid making prescriptive judgements about how something "should" be pronounced but we still allow the description to be placed in a wider perspective.

\section{Data}

Fifteen English-major female teacher trainees at the Hong Kong Institute of Education (HKIEd) were interviewed by an expatriate academic professor (the third author of this paper), who is a speaker of RP British English. In all cases, the interview began 
with the question "Can you tell me what you did on your last vacation?" and then it progressed to discuss this and various other topics. The rationale behind the use of this question was to ensure that the recordings are directly comparable with those that constitute the NIE Corpus of Spoken Singapore English (Deterding 2003; Deterding and Low 2005; Kirkpatrick and Saunders 2005), which similarly opened with the same question asked to English-major teacher trainees being interviewed by an expatriate male speaker of RP British English (the first author of this paper).

The interviews all took place in a recording studio at HKIEd. The data was recorded directly on to a computer using WavePad software with a high quality JVC MV-110 microphone at $44.1 \mathrm{kHz}$ sampling rate.

The speakers will be referred to as F1 to F15. All fifteen speakers use Cantonese as their home language. They were all aged between 22 and 24 at the time of the recording, and all had attended English-medium high schools in Hong Kong. Most stated that English is their second language and Mandarin their third, though F9 gave Mandarin as her second language, F4 gave Mandarin and English as equal, and F1, F2 and F12 did not mention Mandarin. Apart from a visit of up to fifteen weeks to England, Canada or Australia for an immersion programme during the course of their studies at HKIEd, none of the subjects had ever lived in an English-speaking country for more than one month except for F4, who had once stayed in the USA for five 
weeks.

The recordings lasted between 92 and 219 seconds (average 160 seconds). Excluding stuttering repetitions, corrections, and pause particles (er, $\mathrm{mm}$, yeah), the total number of words spoken by the interviewees was 3957, so the average was 283 per speaker. Some of them spoke with almost no further prompting by the interviewer after the first question, with F11 speaking continuously for over 170 seconds about her experiences as a clerk in a school and then about helping to run the Hong Kong population census, and both F3 and F8 only had one additional prompt. Others, however, needed more encouragement, and for both F7 and F13 there were eight questions or other prompts by the interviewer.

Brief details about the speakers and the interviews are shown in Table 1.

TABLE 1 about here

\section{Analysis}

After the data had been transcribed orthographically, the vowels, consonants, rhythm and stress placement were analysed. For the incidence of sounds in words containing $\mathrm{TH}$, the reduction of final consonant clusters, and the pronunciation of potentially reduced vowels in content and function words, both the first and second author of this paper listened to an agreed list of tokens and indicated the sound that they heard in each token. Overall, there was $78.7 \%$ agreement between the two listeners for the $\mathrm{TH}$ 
sounds, $91.3 \%$ agreement for final consonant clusters, and $78.5 \%$ agreement for the incidence of reduced vowels. For each case of disagreement, the token was investigated once more and a decision was made based on repeated listening and also visual inspection of a digital spectrogram generated using Praat software (Boersma and Weenink 2007). For the quality of stressed vowels, measurements of the first two formants were made using Praat. Details of the analysis and measurements will be provided in the following sections.

Here, we will first consider the extent of an American accent in our data, as this has a substantial influence on some of the other features to be considered, especially the quality of vowels. Next, we will analyse the consonants and then the vowels of Hong Kong English before we finally discuss the rhythm and stress placement.

\section{American Accent}

While the accent of most people in Hong Kong is based on British English, as might be expected after the long colonial history of the territory under British rule, a substantial minority prefer to adopt a North American style of speech. Bolton and Kwok (1990) report that about ten percent of their respondents stated a preference for an American accent.

Of the fifteen students in the current study, six have some clear American influences in their speech. Two of them (F7 and F14) show a fairly consistent 
American accent, even though F7 has never lived in North America and F14 was just there for a few weeks during her immersion programme. For example, in extract 1, even though the British interviewer uses [a:] in last, F14 replies with [æ] in the same word, as is usual for the American pronunciation of words such as last from the BATH lexical set (Wells 1982: 133), and in extract 2 the same speaker uses [a: ] rather than [ $\mathrm{b}]$ in lot, flaps the medial [t] in lot of, and has a final $[\mathrm{r}]$ in there, all which are typical features of American pronunciation (Wells 1982: 242-8).

$1 \quad$ Int: What did you do on your last [la:s] vacation?

F14: In my last [læst] vacation ...

2 we went to a lot of [la:rə] places there [ðer]

Four other subjects (F5, F6, F8 and F9) have a more mixed accent, mostly using non-prevocalic $[r]$ but otherwise showing a combination of British and American features. In extract 3, for example, F5 has a final $[r]$ in for (together with a full vowel in this function word, to be discussed below), but she also has [j] in students, something we would not expect with a truly consistent American accent (Wells 1982: 247).

3 the camps are for [fo:r] erm some young students [stju:dəns] $\{\mathrm{F} 5: 12\}$

In fact, even some of the other speakers have some traces of American influence. For example, F11 uses a mostly non-rhotic accent, and, as illustrated in extract 4, she 
has $\left[a_{\mathrm{r}}\right]$ in past, but then she pronounces chance [æ] even though both these words belong to the BATH lexical set in which most Americans would have [æ].

4 in the past [pa:s] few vacations and erm I I got a chance [tææns] to talk with all kinds of people

Overall, the figure of six out of fifteen subjects showing a clear North American influence (which excludes the occasional American features of F11 as illustrated in extract 4) is much higher than the ten percent observed by Bolton and Kwok (1990). It is also somewhat larger than the comparable figures for Singapore. Poedjosoedarmo (2000) reports that $24 \%$ of Chinese Singaporean university students used a non-prevocalic $[r]$ at least once when reading a passage and just $11 \%$ used [æ] in words from the BATH lexical set, and Deterding (2007a) reports that, of the twenty-five Chinese Singaporean undergraduates he recorded reading a passage, six exhibited some rhoticity, which exactly matches the figure of $24 \%$ reported by Poedjosoedarmo. More data is needed to evaluate the extent to which American features extend through the Hong Kong student population, but it does seem likely that it is more widespread than in Singapore, and if we compare the figures reported here with those of Bolton and Kwok (1990), it seems that the American influence may be growing. 


\section{TH}

Consistent with the descriptive approach adopted in this paper, we will represent the sounds at the start of words such as think and that as ' $\mathrm{TH}$ ' in order to avoid presupposing how they "should" be pronounced. Of course, although many speakers use the dental fricatives [ $\theta$ ] and [ð] respectively in these words, others do not, including many speakers of inner-circle Englishes. For example some speakers from New York and Ireland use [t] and [d], and people in London may use [f] and [v] (Wells 1982: 515, 429, 328).

Because of their variable realisation in Englishes around the world, the TH sounds are the only consonants that are absent from the Lingua Franca Core (LFC), the inventory of sounds of English that Jenkins (2000) suggests are essential for international communication and so should be the focus of teaching. The TH sounds are also something of a shibboleth in new varieties of English such as that of Singapore (Low and Deterding 2002), which is why we will consider them first.

It has been widely observed that voiceless $\mathrm{TH}$ is sometimes pronounced as $[\mathrm{f}]$ in Hong Kong English (Luke and Richards 1982; Bolton and Kwok 1990; Hung 2000), and our data confirms these reports. Voiceless TH occurs 61 times in the interviews: 42 times in initial position, 10 times in medial position, and 9 times in final position. The pronunciations found in the tokens in these three positions are shown in Tables 2, 
3 and 4 respectively. In initial position, 27 tokens are pronounced with $[\theta], 14$ with [f], and just one token of three has $[\mathrm{t}]$; in medial position, $[\theta]$ is most common, but $[\mathrm{t}]$ occurs in two tokens of something and omission occurs once; and in final position, [f] is most common. Before we try to conclude anything about the distribution of these sounds, we should note that all four tokens of youth occurred with the same speaker, F1, who was discussing her experiences as a youth representative at a Girl Guides Association meeting.

\section{TABLES 2, 3 AND 4 ABOUT HERE}

In fact, the instance of the various sounds is mostly dependent on the identity of the speaker. Table 5 shows the incidence of the various sounds according to speaker, and it can be seen that only six of the subjects (F3, F5, F9, F10 and F11) exhibit variation, while the others are consistent in using $[\theta]$ or $[f]$.

\section{TABLE 5 ABOUT HERE}

One instance of variation can be seen in extract 5 , which occurs at the start of the interview of F3. She uses [t] in the first instance of three, then she uses [f] in the same word immediately after, and finally she has $[\theta]$ in think.

$5 \quad$ F3: last vacation I read three [tri: $]$ books

Int: Oh.

F3 yeah um three [fri: ] very interesting books I think [OInk] $\{$ F3:4 $\}$ 
However, this kind of variation is the exception rather than the norm. This contrasts with the situation in Singapore where trainee teachers often alternate, for example using $[\theta]$ at the start of reading a passage but then switching to [t] later on, perhaps when they are being less careful about their articulation. In the one hour of conversational data for a single speaker analysed in Deterding (2007b: 15), there are 71 tokens of $\mathrm{TH}$ at the start of content words and among them there are 37 instances of $[\theta]$ and 34 of $[t]$ without any clear pattern, except that $[\theta]$ tends to occur in the phrase I think and [t] occurs after a pause. We would need more extensive data from each speaker in our Hong Kong data to check whether Hong Kong speakers really are mostly consistent in their usage, as has been suggested here, or whether there is regular variation as is found in Singapore.

It is interesting to compare the Hong Kong use of [f] in words beginning with voiceless TH with the patterns found in the rest of South-East Asia. In Singapore (Wee 2004), Malaysia (Baskaran 2004), Brunei (Mossop 1996) and indeed the English spoken in most of the ASEAN countries (Deterding and Kirkpatrick 2006), when a sound other that $[\theta]$ is used for initial voiceless $T H$, it is generally $[t]$ that is adopted, even though there are a wide range of first languages among these different speakers. We can therefore describe use of [t] for voiceless initial $\mathrm{TH}$ as an areal feature throughout most of South-East Asia. In contrast, in the English spoken in 
China, [s] tends to be used (Deterding 2006), and the same occurs in Taiwan (Chung 2005). But Hong Kong is alone in adopting [ $\mathrm{f}]$, the sound that is becoming increasingly common with young people in Britain (Przedlacka 2002, 2005). As we will see for some other features below, Hong Kong English seems to be unique in the region in apparently following some trends from Britain rather than adopting patterns that are emerging in the rest of South-East Asia.

For voiced $\mathrm{TH}$, especially for the sound at the start of function words such as that and then, in Hong Kong if a sound other than [ð] is used, it is generally [d], as is illustrated in extracts 6 and 7.

6 even though [dov] we can see

$7 \quad \mathrm{um} \ldots$ there $[\mathrm{d} \varepsilon]$ was a strike

In the English typical of London, [V] tends to occur for voiced TH in the middle of words such as brother and mother. We have no tokens of medial voiced TH in content words such as brother in our data - it seems that most of the speakers chose to do something independent of their families during the vacation that they discussed during the interview. However, we do find [d] in whether in extract 8 , and colleagues at HKIEd have confirmed that [d] rather than [v] is more likely to occur in words such as brother.

8 whether [wedə] the school $\{\mathrm{F} 9: 68\}$ 


\section{Final Consonant Clusters}

There is a tendency in Hong English for final consonant clusters to be simplified, particularly with the omission of the final consonant. Eleven of the speakers use the phrase last vacation or last summer near the start of their first utterance, and eight of them omit the $[\mathrm{t}]$ in last. However, we must be careful to put this in context, as RP speakers regularly simplify consonant clusters in cases like this (Fabricius 2002). Indeed, in our data the British interviewer always includes the phrase last vacation in his opening question, and in all but one instance, he omits the [t]. So, in fact, the Hong Kong speakers actually omit the [t] in this phrase less often than the RP speaker.

We will therefore focus on word-final consonant clusters before a pause or before a word beginning with a vowel, environments where omission of the final consonant would be less common in British or American English. Tokens where the first consonant in the cluster is an [l] are avoided, as there is widespread vocalisation of dark [I] (to be discussed below), so in fact there is no consonant cluster in words such as gold. We will therefore just consider tokens with a word-final plosive, [t], [d] or $[\mathrm{k}]$, in phrases such as most of, friend and, think it's and also utterance final tokens. Altogether, there are 69 tokens of potential word-final plosives that fit this description. 
The results for pronunciation of these word-final consonant clusters are summarised in Table 6 , where it can be seen that in nearly $54 \%$ of the tokens the final plosive is omitted.

\section{TABLE 6 ABOUT HERE}

One factor that should be considered here is the frequency of the phrase kind of, which occurs eight times, and in which the [d] is omitted in every case. The regular deletion of a plosive from the middle of a common fixed phrase like this is not unexpected, and in the remaining eight tokens of final [d], the plosive is omitted just twice.

One other common fixed phrase is I think, which occurs before a vowel or pause 16 times, and the $[\mathrm{k}]$ is omitted in nine of them. (The only other instance of word-final [k] in the tokens considered is in ask a question, and the [k] is omitted here.)

Peng and Setter (2000) also document in some detail the omission of morpheme-final [t] and [d] in citation forms of words in Hong Kong English. This kind of omission almost always occurs when the plosive is surrounded by two other consonants, such as the [t] in the middle of adjustment and restful. Omission of a word final plosive is rare in their data, though there is instances of hand pronounced as [hen] (p. 98) and amend as [əmen] (p. 100). 
The incidence of omission of final plosives from consonant clusters is rather less than the comparable figure for Singapore English. Gut (2005) reports that just 17.5\% of instances of final [t] and [d] are retained in consonant clusters before a vowel in data from the NIE Corpus of Spoken Singapore English, which, as we mentioned above, has almost identical recording conditions to those of our Hong Kong data.

\section{Extra Consonants}

Analysis of new varieties of English often focuses on omission of consonants, as in the previous section, but less attention is usually given to the insertion of consonants. However, Setter and Deterding (2003) have shown that unexpected extra consonants, especially [t] and [s], can occur in both Hong Kong and Singapore English, and Stibbard (2004: 134-5) notes the occurrence of an extra [t] quite regularly in his data of recordings of undergraduates at Hong Kong Baptist University, with this sound occurring on the end of words such as option, line, pin, one, animals, however, finally, so, day and actually.

In our data, an extra [t] rarely occurs, though F1 does exhibit this phenomenon twice, both times with the word leadership, as in extracts 9 and 10 .

9 leadership [lirdəSIpt] in the world-wide setting

10 erm leadership [lirdəSIpt] ... yeah

Rather more common is the occurrence of an unexpected [s], as illustrated by 
extracts 11 to 14 .

11 I went [wens] there

$\{\mathrm{F} 1: 17\}$

12 F12: I went [wens] to Shanghai

Int hmm

F12 because I went [wens] there for an exchange

$\{\mathrm{F} 12: 9\}$

13 which is ... very ... different [dIfrons] from what I have done $\{$ F11:144\}

14 they have the responsibility to erm ... accept [æseps] this offer

$\{\mathrm{F} 11: 170\}$

Note that all these examples involve [s] occurring in place of [t], and rather than saying that there is an inserted [s], we might instead interpret these as instances of heavy aspiration for the [t] with the result that it sounds rather like an [s]. Support for this is found in extract 15, where greatly sounds like 'gracely'.

15 felt most greatly [greisli] is that I can meet friends from all around the world

$\{\mathrm{F} 1: 64\}$

However, we also occasionally find [s] replacing a final [d], as in extract 16 , and this is unlikely to represent heavy aspiration after a voiced plosive. Perhaps, in this case, it reflects a spurious $-s$ suffix.

16 on the one hand [hæns] I can

$\{\mathrm{F} 11: 63\}$ 


\section{Initial Consonant Clusters}

Researchers have written about the confusion between [l] and [r], so Bolton and Kwok (1990: 153) mention flight as [fraIt] and Stibbard (2004: 131) discusses the [r] in bridge being pronounced as [l] or omitted. Note that both these examples involve initial consonant clusters, and there seems to be less likelihood of any overlap between $[\mathrm{l}]$ and $[\mathrm{r}]$ when they occur as single consonants. Indeed, in our data, all instances of $[r]$ being pronounced as $[\mathrm{I}]$ or omitted occur when it is the second sound in a consonant cluster.

First, let us consider some data from just one speaker. Extracts 17 to 23 all involve the speech of F10.

17 also it was very crowded [klaudid]

18 was so crowded [klaudid]

$\{\mathrm{F} 10: 71\}$

19 it's very also crowded [klaudid]

20 built to protect [proutekt] er China

$\{\mathrm{F} 10: 144\}$

21 on producing [prodju:sin] some $\{\mathrm{F} 10: 183\}$

22 IT products [prodəts]

$\{\mathrm{F} 10: 185\}$

23 I'm very proud [praud] of being a Chinese

$\{\mathrm{F} 10: 158\}$

Note that all three instances of crowded in extracts 17 to 19 involve use of [l] instead of $[\mathrm{r}]$ after the initial $[\mathrm{k}]$, but none of the tokens involving initial [pr] in 
extracts 20 to 23 exhibit this substitution. So, for this speaker, is the use of [l] in place of [r] a lexical phenomenon, affecting just some words such as crowded? Or is it phonological, being found in initial $[\mathrm{kr}]$ but not $[\mathrm{pr}]$ ? We would really need more data from F10 to resolve this. However, informal observation of speakers in Hong Kong indicates that $[\mathrm{pl}]$ may occur at the start of problem, so, for other speakers at least, the use of [l] in place of $[r]$ does extend to a preceding [p] (partly, in this case, in anticipation of the [bl] later in the word).

Let us consider instances of replacement or omission of $[r]$ and $[\mathrm{l}]$ from the other speakers in extracts 24 to 28 .

24 I applied [^paId] for that job

$\{\mathrm{F} 11: 121\}$

25 one is in primary [pasməri] school

26 I mostly spent on preparing [pIperın] the teaching materials

$\{\mathrm{F} 13: 27\}$

27 I've got a little bit free [fi: ] time

28 I don't how to say in English [Ingrif] but erm

$\{$ F12:110\}

Apart from the use of $[\mathrm{r}]$ instead of $[\mathrm{l}]$ in the middle of English in extract 28, these examples all involve omission of [l] or [r] after labial consonants. Further investigation is needed to find out if it is true that approximants following the initial velar consonants $[\mathrm{k}]$ and $[\mathrm{g}]$ are sometimes replaced while approximants following initial labials such as $[\mathrm{p}]$ and $[\mathrm{f}]$ are more likely to exhibit omission. 


\section{[n] / [l] Conflation}

There has been much discussion about the conflation of $[\mathrm{l}]$ and $[\mathrm{n}]$ in the syllable onset (Luke and Richards 1982; Bolton and Kwok 1990; Hung 2000). Wong and Setter (2002) have investigated this phenomenon in some detail using conversational data from seventeen students at Hong Kong Polytechnic University, and they conclude that use of $[\mathrm{l}]$ in place of $[\mathrm{n}]$ is rather more common than the inverse, probably as a result of influence from recent changes in Cantonese where [I] is increasingly used for words that traditionally began with [n]. Indeed, Tong and James (1994: 6) note that use of [l] in place of initial [n] is widespread among young speakers of Cantonese, and Zee (1999: 60) states that [n] nowadays "rarely occurs in syllable-initial position" in Hong Kong Cantonese.

One might note that conflation of [1] and [n] also occurs in the English of speakers from central Chinese provinces such as Sichuan and Jiangsi, but in these cases it is more usual for [n] to occur in place of [l], with the result that law and last may begin with [n] (Deterding 2006).

In our data, conflation of [l] and [n] is rare, and we just find two examples, as in extracts 29 and 30. In 29, the [n] at the start of eleven may be influenced from the two instances of $[\mathrm{n}]$ in the preceding word and also the $[\mathrm{n}]$ at the end of eleven. Extract 30 is harder to interpret, as Canada sounds rather like 'calendar'. 
30 the teachers ... come from ... Canada [kælındə]

It is hard to determine why this phenomenon seems to be less frequent with these students from HKIEd than comparable data from the undergraduates at Polytechnic University studied by Wong and Setter (2002).

\section{L-vocalisation}

Use of a vowel (vocalisation) in place of dark [I] has been reported as common in Hong Kong English so that will may be [WIU] and oral may be [Jrou] (Bolton and Kwok 1990: 153), though Hung (2000: 350) prefers an alternative notation using [w] so that feel is [fiw] and dull is [d $\mathrm{dw}$ ]. Hung also notes that deletion rather than replacement occurs after a back vowel, so call is [kJ] and cool is [ku].

Our data similarly exhibit many instances of vocalisation or deletion of dark [I], including extracts 31 and 32 in which the final [I] is deleted. In fact, in 31 wall sounds just like war, and these two words would presumably be homophones for F10 as she does not generally have American post-vocalic [r]. (The fronted quality of the vowel in school in extract 32 will be discussed in the next section.)

31 I have been to the Great Wall [Wo: and er $\{\mathrm{F} 10: 34\}$

32 my alumni school [skt: $]$ my secondary school [sk $\mathrm{s}:$ ]

$\{\mathrm{F} 11: 47\}$

Vocalisation of dark [l] is extremely common in many varieties of English, 
including that of Singapore, where Tan (2005: 50) reports that about 65\% of tokens in the NIECSSE data are vocalised or deleted. In fact, vocalised [I] is common in many varieties of British English, including Estuary English (Cruttenden 2001: 203), and Wells (1982: 259) suggests it might soon become standard. In British varieties of English, vocalisation does not involve deletion, so it is maybe not common for war and wall to become homophones. However, if we remember that some words in which there is a final plosive such as walk, could and folk once had an [l] in them (as indicated by the spelling), perhaps Hong Kong English is at the forefront of the development of the language in extending the deletion of [l] after a back vowel to words in which it is in final position.

\section{Monophthongs}

The quality of monophthong vowels can be investigated acoustically by measuring the first two formants, converting them to an auditory Bark scale, and then plotting the values on a chart of the first formant (on the y-axis) against the second formant (on the $\mathrm{x}$-axis) to offer an estimate of their open/close and front/back quality.

Clear, stressed instances of all the monophthongs in the fifteen interviews were measured following the methodology outlined in Deterding (2003). In instances where a speaker repeated a word, only one token of the word was measured, to avoid the results being influenced by idiosyncratic pronunciations by any one speaker. 
Tokens following the approximants $[\mathrm{w}],[\mathrm{j}]$ and $[\mathrm{r}]$ were avoided, and so were those before [ฤ] and dark [l], as all these sounds have severe co-articulatory effects on the vowel. For tokens of $[\mathrm{a:}]$, care was taken to avoid words in the BATH lexical set for those speakers with an American accent, especially F17 and F14, and similar care was taken to exclude from the data for [D] any words from the LOT and CLOTH lexical sets for those with an American accent. On average, a total of 39 tokens were measured for each vowel, though inevitably there were fewer tokens of relatively rare vowels such as [ひ] and [3:], for which just 18 and 20 tokens were measured respectively. The results are plotted in Figure 1, with front vowels shown on the left and open vowels at the bottom, as is usual in vowel plots (Ladefoged 2001).

\section{FIGURE 1 ABOUT HERE}

It can be seen from Figure 1 that there is a pairing of the vowels, especially [i: and [I] as well as [e] and [æ], which confirms the findings of Hung (2000) and also Bolton and Kwok (1990) that these vowels tend to be merged in Hong Kong English. Similarly, there is only a small difference between [כ: $]$ and [D], though it is not clear if they are fully merged.

It is valuable to compare this plot with the vowels of another variety of English, and Figure 2 shows the vowels of female undergraduate speakers of Singapore English measured in almost identical circumstances to our Hong Kong data and 
reported in Deterding (2003).

\section{FIGURE 2 ABOUT HERE}

The biggest difference between Figures 1 and 2 lies in the location of [ur], which in Singapore is a fully back vowel but in Hong Kong seems to be fronted, and the fronted quality for this vowel is one of the most salient features of our data. This does not agree with the findings of Hung (2000), who plots [u:] as fully back. Deterding (2007a) has discussed the selection of words used by Hung, as his measurements involve the bimorphemic word whod, so the quality of this vowel may be influenced by the monomorphemic who in which there is no final consonant. However, in the data considered here, the fronted quality of the GOOSE vowel is found in tokens of do and two, both of which have no final consonant, as well as in food, as in extracts 33 to 37 , so it is not clear why there is such a difference between our results and those of Hung (2000). It is possible that the citation vowels that he investigates are rather different from those found in conversational speech.

33 as well as I do [dtr]

34 to do [ $\left.\mathrm{dtu}_{\mathrm{i}}\right]$ the assignments

35 I did two [tt: $]$ part-time jobs

36 I've done ... two [ttr $]$ jobs

37 Portuguese food [ $\mathrm{ftr}: \mathrm{d}]$ 
Indeed, the fronted quality of this vowel extends to the function word to, as in extracts 38 to 40 .

38 for me to $[\mathrm{tt}:]$... you know, re-read some, a book

39 we went to [tu: $]$ the Empire State Building

40 getting to [tt: $]$ my final year

We might consider briefly where the influence for this fronting of [u:] comes from. Although Zee and Lee (2007) report that what was originally a close back vowel has become fronted in one southern dialect of Chinese, the Yongding variety of Kejia (Hakka), there is no evidence from Zee (1999) of the same happening to [ur] in Hong Kong Cantonese, so it seems unlikely that the indigenous languages of Hong Kong have influenced the pronunciation of English [u:]. However, the fronting of words in the GOOSE lexical set is a well-known phenomenon in modern British English (Przedlacka 2005), for which measurements by Hawkins and Midgley (2005) have confirmed that it is increasingly common among young RP speakers, and it also occurs in New Zealand English (Bauer and Warren 2004). This is one more example, therefore, where Hong Kong seems to be affected by modern trends in the pronunciation of inner-circle Englishes while Singapore is immune from this kind of influence. We might note, however, that Salbrina (2006) has noted the fronted quality of $\left[u_{i}\right]$ in Brunei English, so unlike the pronunciation of $\mathrm{TH}$, for the realisation of [u: ] 
maybe Hong Kong is not alone in South-East Asia.

\section{FACE and GOAT}

Words in the FACE and GOAT lexical sets are pronounced with the diphthongs [eI]

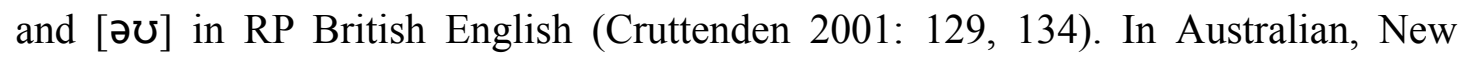
Zealand and South African English, they are also pronounced as diphthongs, often with substantially more diphthongal movement than that found in RP (Wells 1982: 597, 609, 614). However, these two vowels are pronounced as long monophthongs that might better be represented as $\left[\mathrm{er}_{\mathrm{i}}\right]$ and [o:] in many other varieties of English including those of Scotland, Wales and many people in North America (Wells 1982: 407, 382, 497). These two vowels also tend to be produced as monophthongs in Singapore (Wee 2004), Malaysia (Baskaran 2004) and throughout many of the ASEAN countries of South-East Asia (Deterding and Kirkpatrick 2006).

In our data, the quality of the FACE and GOAT vowels was measured by obtaining the frequencies of the first two formants at two positions in each vowel, one towards the start of the vowel and one towards the end (with care taken to avoid any formant transitions). Similar to the measurements of monophthongs discussed in the previous section, vowels following [W], [j] and [r] were avoided, and also those before [l]. Attempts were made to measure the vowel in five different words for both FACE and GOAT for all fifteen speakers, though inevitably it was not possible to find 
five tokens for one or both of the vowels in some of the shorter interviews. A total of 65 tokens of FACE and 57 of GOAT were measured, and the average trajectories for the two vowels are shown in Figure 3. These trajectories are very similar to those shown in Hung (2000) for the same two vowels.

\section{FIGURE 3 ABOUT HERE}

As both vowels are (potentially) closing diphthongs, we expect the first formant to decrease if the vowel is actually realised as a diphthong, and a simple but quite effective estimate of the extent to which these vowels are diphthongs can be derived by considering the slope of the first formant. Using the same methodology as Deterding (2000), the change in the frequency of the first formant is divided by the duration between the first and second measurements, and we thereby obtain a Rate of Change (ROC) value for each vowel (in Hz per second). The more negative this ROC value is, the greater the estimated diphthongization of the vowel. In Table 7, the average values for the Hong Kong data are compared with those for the Singapore and RP British English data from Deterding (2000), and it can be seen that the Hong Kong values are much closer to the British than the Singapore ones.

TABLE 7 ABOUT HERE

T-tests suggest that the difference between the Hong Kong and Singapore data is highly significant both for FACE $(\mathrm{t}=7.95, \mathrm{df}=33, \mathrm{p}<0.0001)$ and also for GOAT 
$(\mathrm{t}=6.26, \mathrm{df}=33, \mathrm{p}<0.0001)$, but there is no significant difference between the Hong Kong and British data for FACE $(\mathrm{t}=1.50, \mathrm{df}=23, \mathrm{~ns})$ and only a marginally significant difference for GOAT $(\mathrm{t}=2.67, \mathrm{df}=23, \mathrm{p}<0.05)$. It seems that, for the degree of closing movement in FACE (as represented by the change in the first formant), Hong Kong speakers have a vowel that is similar to people in Britain, and for GOAT, there is only a small difference, though when we consider the trajectories that were shown above in Figure 3, we should note that the starting point in GOAT is rather less fronted than that for RP speakers in Britain (Ladefoged 2001: 45). One might also note that the trajectories for FACE and GOAT in Hong Kong English are very similar to those shown by Zee (1999) for the [ei] and [ou] vowels of Cantonese.

\section{Vowel Reduction}

Often a reduced vowel (a schwa) in the unstressed syllables of polysyllabic words does not occur in Hong Kong English when it might be expected in other varieties of English. For example, Bolton and Kwok (1990: 152) report that in their data familiar has $[\varepsilon]$ in its first syllable, and Peng and Setter (2000: 88) transcribe both accept and account with a full vowel at the start.

Here we will only consider words which are shown with a reduced vowel in their first syllable in the first entry listed in Jones et al. (2003), so words like activities and fantastic are excluded. We will also exclude consideration of vacation as this word 
was used in the initial question by the interviewer, so his pronunciation may have influenced the way it was said by these Hong Kong speakers. We will only consider the first syllable of polysyllabic words, as van Bergem (1995) has shown that listeners are most consistent in their judgements of the occurrence of reduced vowels in this first syllable. We will restrict our analysis to words with 'a', 'o' or 'u' in the spelling of this first syllable, as unstressed syllables spelt with ' $i$ ' or ' $\mathrm{e}$ ' are often pronounced as [I], and it is hard to determine whether [I] is a reduced vowel or not. Finally, in cases where a speaker repeats a word, we only consider the first token. The results are shown in Table 8. In cases where more than one speaker uses a word (such as around), the number of tokens is included in parentheses after the word. Two words, attraction and traditional, appear twice in the table, as in each case one speaker uses a full vowel while another uses a reduced vowel. From Table 8 , it can be seen that when there is an ' $a$ ' in the spelling, a reduced vowel occurs in 20 out of the 30 tokens.

\section{TABLE 8 ABOUT HERE}

It has been reported that, in Singapore English, a full vowel tends to occur in the first syllable of words in which the syllable is closed off with a consonant, such as absorb which would be syllabified as [æb.zว:b] (where [.] shows the syllable boundary), but a reduced vowel is more common in words where, after syllabification, the first syllable has no closing consonant, such as abroad which is [ə.bro:d] 
(Deterding 2005). Although this rule is not watertight, as Deterding (2007b: 29) reports that, for the subject whose speech he analysed in detail, cassette has an unexpected full vowel in its first syllable while advised has a reduced vowel, the generalisation does generally hold for Singapore English. Unfortunately, in the Hong Kong data considered here, there is only one word in the closed-first-syllable category: accept. Further data is needed to see if other words in this category also tend to have a full vowel in the initial syllable. We can note, however, that the other words that were found to have a full vowel in their first syllable (alumni, applied, association, attraction, cannot, magician, patrol, statistics, traditional) all have an open first syllable, as in all cases the consonant(s) at the end of the first syllable can be regarded as belonging in the second syllable (according to the Maximum Onset Principle). So it seems that a full vowel in the first syllable might be more widespread in Hong Kong than Singapore English.

In Table 8, eight out of the fourteen tokens with an 'o' in the spelling of their first syllable are pronounced with a full vowel, and this matches the findings of Heng and Deterding (2005) for Singapore English that polysyllabic words with an unstressed first syllable with an 'o' in the spelling tend to have a full vowel.

For ' $u$ ', we only have a single token, surprised, but that has a reduced vowel.

So far we have only considered the unstressed first syllable of polysyllabic words. 
Other syllables are sometimes affected, and Bolton and Kwok (1990: 152) mention the final syllable of grammar as having a full vowel rather than a schwa. In our data, extract 41 provides an instance of certificate with a full vowel in its final syllable; but, as discussed above, auditory judgement of non-initial syllables tends not to be too reliable, so we will not investigate this further.

41 giving out all the certificate [sətIfIkeit] for the students $\{\mathrm{F} 11: 55\}$

Setter (2003) reports that in her recordings of students at Hong Kong Polytechnic University, just $19.3 \%$ of all syllables were weak, while in comparable data of British English, $34.8 \%$ of all syllables were weak. These counts include monosyllabic words as well as polysyllabic ones, and of course the most common occurrence of reduced vowels in many varieties of English is not in the unstressed syllables of polysyllabic words but rather in the weak forms of function words.

We have already mentioned the use of [ $\mathrm{H}:$ ] in to in extracts 38 to 40 and also the use of a full vowel in for in extract 3. We will now consider the pronunciation of function words in more detail. Some function words, such as in, on and off have no weak form, so we will not consider those. In addition, in British English, to before a vowel tends to be [tu] rather than [tə] (Jones et al 2003: 539), so we will only consider to before a consonant. Finally in Hong Kong the articles $a$ and the nearly always have a reduced vowel and are rarely pronounced in their stressed forms [eI] 
and [ð ${ }_{i}$ ] $]$, illustrating that the schwa does sometimes exist quite systematically in our data. We will therefore look at the occurrence of reduced vowels in other function words: and, but, of, for, to (before a consonant), from, that (as a subordinator), as and was. The quality of the vowel in the first ten tokens of these function words uttered by each speaker was investigated, though no more than three tokens of the same word were considered from each speaker (as some speakers used the word and rather often). In total, therefore, 150 tokens were investigated, and the results are shown in Table 9.

\section{TABLE 9 ABOUT HERE}

We can see from Table 9 that the overwhelming majority of these function words (118 out of 150 , or $79 \%$ ) have a full vowel, though there are a few which have a reduced vowel, and in fact most of the tokens of from have a reduced vowel. These figures are very similar to those found for the conversational data of the Singapore speaker studied in Deterding (2007b), where $80 \%$ of a similar set of function words were found to have a full vowel.

In fact, regular use of full vowels where reduced vowels might be expected in inner-circle varieties of English is found in new Englishes that are emerging around the world, such as that of speakers from the Caribbean (Wells 1982: 570), West Africa (Wells 1982: 639), India (Kachru 2005: 46), the ASEAN countries (Deterding and Kirkpatrick 2006), and China (Deterding 2006a). In fact, it seems that this is 
becoming the norm for new varieties of English.

\section{Rhythm}

One of the consequences of the relative absence of reduced vowels is that the English of places like Hong Kong and Singapore is perceived to have syllable-based rhythm (Low, Grabe and Nolan 2000; Setter 2003) instead of the rhythm based on an alternation of strong and weak syllables that gives rise to the perception of stress-based rhythm in most inner-circle varieties of English. In fact, one of the most widely used metrics for comparing the rhythm of different language varieties, that of Low et al. (2000), is based entirely on a comparison of the duration of vowels in neighbouring syllables, principally because stress-based languages tend to have fewer reduced vowels, with the result that neighbouring vowels will tend to be more even in their duration.

In our Hong Kong data, we do indeed find some clear instances of syllable-based rhythm, as in extracts 42 to 45 .

42 for most of the time we were walking

43 so I taught them some skills to

44 my Mandarin is not good enough so I never

45 I've been briefly to Vietnam

$\{\mathrm{F} 15: 151\}$

However, we need to be careful here. Crystal (1995) notes that syllable-based 
rhythm also sometimes occurs in British English, for example when talking to infants and in television slogans, so a few instances of this kind of rhythm as presented above do not prove anything. Perhaps the speakers were being deliberately precise at those moments, or maybe they were using syllable-based rhythm as a kind of slowing down mechanism, to allow them time to think. We really need an in-depth investigation using a formal metric to measure the rhythm, such as that of Low et al (2000), in order to quantify the speech rhythm of Hong Kong English, but that is beyond the scope of this paper.

\section{Sentence Stress}

In Hong Kong English, Bolton and Kwok (1990: 154-5) report that the main sentence stress (the 'tonic') tends to occur at the end of an utterance even when elsewhere there is an emphatic word which might be expected to become the focus of information. Furthermore, they observe that repeated information tends not to receive reduced emphasis in a process of de-accenting.

One instance of repeated or predictable information being given emphasis is in extract 46, where some of the most prominent syllables are capitalised and underlined. Both first and London are repeated, yet they still get tonic stress, and the final word city, which might be regarded as predictable (as we all know that London is a city) still receives substantial emphasis. 
46 that was my first time to London because um ... the immersion semester was the FIRST time I went to England, and er yeah, so my stay in

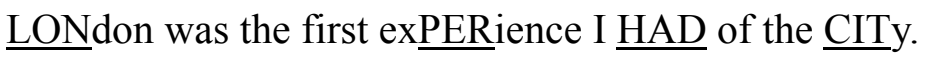

This absence of de-accenting has also been noted for Singapore English (Low 1998; Goh 2000; Levis 2005).

One other pattern involving stress placement that sometimes occurs in our Hong Kong data is the unexpected emphasis on pronouns, both when they function as the subject as in extract 47 and when they are possessive determiners as in 48 . Note also the unexpected stressing of the demonstrative determiner this in extract 49 .

$47 \quad$ WE enjoyed that a lot

48 I will tell you about $\underline{\mathrm{MY}}$ summer holiday

49 I enjoyed $\underline{\text { THIS job very much }}$

The stressing of pronouns and determiners like this is also found in Singapore English (Deterding 2007b: 33) and throughout the ASEAN region (Deterding and Kirkpatrick 2006).

\section{Conclusion}

A few of the patterns observed above, particularly the conflation of initial [l] and [n], are unique to Hong Kong (and maybe other parts of South China), and they can be ascribed to the influence of Cantonese (and other local varieties of Chinese). Some 
other patterns, particularly the conflation of long and short vowels as well as $[\mathrm{e}]$ and [æ], the absence of reduced vowels, the use of syllable-based rhythm and the stressing of pronouns, are shared with the English of Singapore and other countries in South-East Asia, and indeed some of them seem to be widespread in many new varieties of English. A third category of features, including the simplification of final consonant clusters and the vocalisation of dark [l], probably occur in most varieties of English, including those in the inner-circle. However, perhaps the most interesting features of Hong Kong English belong to a fourth category: features which are found in varieties of British English but not in other Englishes in South-East Asia. They include the use of [f] for initial TH in content words, the fronting of [ $\left.\mathrm{u}_{\mathrm{r}}\right]$, and the use of a diphthong for FACE and GOAT. While the last of these might be due to the influence of Cantonese, there is no evidence of fronting of [ $\left.\mathrm{ur}_{\mathrm{r}}\right]$, so this seems to be an influence of modern style of speech in Britain (and also possibly other places such as New Zealand). And for TH, although the consonant inventory of Cantonese (Zee 1999) excludes dental fricatives, so it can be predicted that these sounds might be avoided in Hong Kong English, contrastive analysis is unable to predict which sound will be used instead, and it is somewhat surprising that $[\mathrm{f}]$ is adopted in Hong Kong, possibly under the influence of London English, while the rest of South-East Asia mostly adopts [t] and China and Taiwan adopt [s]. 
Why should Hong Kong English apparently still be influenced by British English in ways that other varieties, such as that of Singapore, are not? Schneider (2003, 2007) posits a five-stage dynamic model for the emergence of postcolonial Englishes, and he suggests that Singapore is in the fourth stage, labeled 'endonormative stabilization', in which standards are increasingly independent of external sources of reference, but Hong Kong is still in the third 'nativization' stage, so to a certain extent it still looks elsewhere for its norms and is only in the process of developing its own identity. In other words, Hong Kong English is only now emerging as an independent variety, while Singapore English is rather more clearly established. One reason for the different status of English in the two former British colonies is that, while English is now spoken as a home language by about half of all young people in Singapore, and furthermore it functions as an inter-racial lingua franca, this is not so much the case in Hong Kong, where Cantonese remains the predominant language (Kirkpatrick 2007a: 140). It will be interesting to see, therefore, whether Hong Kong English continues to develop along the five-stage process to maturity. Now that there is increasing pressure on children in Hong Kong schools to learn Mandarin, and in fact the majority of secondary schools are now Chinese medium, it may indeed happen that the Hong Kong English will also be further influenced by Cantonese and Mandarin and/or fail to develop as expected. Only time will tell. 


\section{References}

Baskaran, Loga. 2004. "Malaysian English: phonology”. In Edgar W. Schneider, Kate Burridge, Bernd Kortmann, Rajend Mesthrie and Clive Upton eds. A Handbook of Varieties of English. Volume 1: Phonology. Berlin: Mouton de Gruyter, 1034-46.

Bauer, Laurie and Paul Warren. 2004. "New Zealand English: phonology”. In Edgar W. Schneider, Kate Burridge, Bernd Kortmann, Rajend Mesthrie and Clive Upton eds. A Handbook of Varieties of English. Volume 1: Phonology. Berlin: Mouton de Gruyter, 580-602.

Boersma, Paul and David Weenink. 2007. "Praat: doing phonetics by computer". $<$ http://www.fon.hum.uva.nl/praat/> (10 July 2007).

Bolton, Kingsley. 2003. Chinese Englishes: A Sociolinguistic History. Cambridge: Cambridge University Press.

Bolton, Kingsley and Helen Kwok. 1990. "The dynamics of the Hong Kong accent: Social identity and sociolinguistic description". Journal of Asian Pacific Communication 1: 147-72.

Chung, Karen. 2005. "The sounds and allophones of Taiwan English III". $<$ http://homepage.ntu.edu.tw/ karchung/intro\%20page\%2029.htm> (21 July 2007). 
Cruttenden, Alan. 2001. Gimson's Pronunciation of English, 6th edn. London: Arnold.

Crystal, David. 1995. "Documenting rhythmical change”. In Jack Windsor Lewis, ed. Studies in General English and Phonetics: Essays in Honour of Professor J. D. O’Connor. London and New York: Routledge, 174-9.

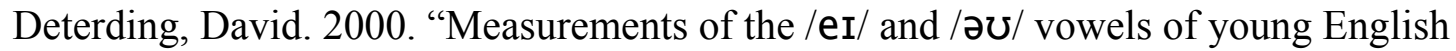
speakers in Singapore”. In Adam Brown, David Deterding and Low Ee Ling, eds. The English Language in Singapore: Research on Pronunciation. Singapore: Singapore Association for Applied Linguistics, 93-9.

Deterding, David. 2003. "An instrumental study of the monophthong vowels of Singapore English”. English World Wide 24: 1-16.

Deterding, David. 2006. "The pronunciation of English by speakers from China". English World-Wide 27: 175-98.

Deterding, David. 2007a. "The Vowels of the Different Ethnic Groups in Singapore”. In David Prescott, Andy Kirkpatrick, Isabel Martin and Azirah Hashim, eds. English in Southeast Asia: Literacies, Literatures and Varieties, Newcastle, UK: Cambridge Scholars Press: 2-29.

Deterding, David. 2007b. Singapore English, Edinburgh University Press. 
Deterding, David and Low Ee Ling. 2005. "The NIE Corpus of Spoken Singapore English". In David Deterding, Adam Brown and Low Ee Ling, eds. English in Singapore: Phonetic Research on a Corpus, Singapore: McGraw-Hill, 1-6.

Deterding, David and Andy Kirkpatrick. 2006. "Emerging South-East Asian Englishes and intelligibility". World Englishes 25: 391-409.

Fabricius, Anne. 2002. "Ongoing change in modern RP: evidence for the disappearing stigma of t-glottaling”. English World-Wide 23: 115-36.

Goh, Christine C. M. 2000. "A discourse approach to the description of intonation in Singapore English". In Adam Brown, David Deterding and Low Ee Ling, eds. The English Language in Singapore: Research on Pronunciation. Singapore: Singapore Association for Applied Linguistics, 35-45.

Gut, Ulrike. 2005. "The realisation of final plosives in Singapore English: phonological rules and ethnic differences". In David Deterding, Adam Brown and Low Ee Ling, eds. English in Singapore: Phonetic Research on a Corpus, Singapore: McGraw-Hill, 14-25.

Hawkins, Sarah and Jonathan Midgley. 2005. "Formant frequencies of RP monophthongs in four age groups of speakers". Journal of the International Phonetic Association 35: 183-200. 
Heng Mui Gek and David Deterding. 2005. "Reduced vowels in conversational Singapore English". In David Deterding, Adam Brown and Low Ee Ling, eds. English in Singapore: Phonetic Research on a Corpus, Singapore: McGraw-Hill, $54-63$.

Hung, Tony T. N. 2000. “Towards a phonology of Hong Kong English". World Englishes, 19, 337-56. (Also in Kingsley Bolton, ed. 2002. Hong Kong English: Autonomy and Creativity. Hong Kong: Hong Kong University Press, 119-40.)

Jenkins, Jennifer. 2000. The Phonology of English as an International Language. Oxford: Oxford University Press.

Jones, Daniel, Peter Roach, James Hartman and Jane Setter. 2003. Cambridge English Pronouncing Dictionary. 16th edn. Cambridge: Cambridge University Press.

Kachru, Braj B. 2005. Asian Englishes: Beyond the Canon. Hong Kong: Hong Kong University Press.

Kirkpatrick, Andy. 2007a. World Englishes: Implications for International Communication and English Language Teaching. Cambridge: Cambridge University Press. 
Kirkpatrick, Andy. 2007b. "The communicative strategies of ASEAN speakers of English as a lingua franca". In David Prescott, Andy Kirkpatrick, Isabel Martin, and Azirah Hashim, eds. English in Southeast Asia: Literacies, Literatures and Varieties. Newcastle, UK: Cambridge Scholars Press: 121-39.

Kirkpatrick, Andy and Neville Saunders. 2005. "The intelligibility of Singaporean English: a case study in an Australian university”. In David Deterding, Adam Brown and Low Ee Ling eds. English in Singapore: Phonetic Research on a Corpus. Singapore: McGraw Hill: 153-62.

Ladefoged, Peter. 2001. Vowels and Consonants: An Introduction to the Sounds of Language. Maldern MA: Blackwell.

Levis, John M. 2005. "Prominence in Singapore and American English: evidence from reading aloud”. In David Deterding, Adam Brown and Low Ee Ling eds. English in Singapore: Phonetic Research on a Corpus. Singapore: McGraw Hill: 86-94.

Low Ee Ling. 1998. "Prosodic prominence in Singapore English". Unpublished PhD thesis, Cambridge University.

Low Ee Ling and David Deterding. 2002. "Recent research into the pronunciation of Singapore English". In Andy Kirkpatrick, ed. Englishes in Asia: Communication, Identity, Power and Education. Australia: Language Australia Ltd, 179-90. 
Low Ee Ling, Esther Grabe and Francis Nolan. 2000. "Quantitative characterisations of speech rhythm: syllable-timing in Singapore English”. Language and Speech 43: $377-401$.

Luke, Kang-kwong and Jack C. Richards. 1982. "English in Hong Kong: functions and status". English World-Wide 3: 47-61.

Mohanan, Karuvannur P. 1992. "Describing the phonology of non-native varieties of a language". World Englishes 11: 111-28.

Mossop, Jonathan. 1996. "Some phonological features of Brunei English". In Peter W. Martin, Conrad Ożóg \& Gloria Poedjosoedarmo, eds. Language Use and Language Change in Brunei Darussalam. Athens, Ohio: Ohio University Centre for International Studies, 189-208.

Peng, Long and Jane Setter. 2000. "The emergence of systematicity in the English pronunciations of two Cantonese-speaking adults in Hong Kong”. English World-Wide 21: 81-108.

Poedjosoedarmo, Gloria. 2000. "A description of the English pronunciation of young educated Singaporeans: a study in multidimensional variation". In Adam Brown, David Deterding and Low Ee Ling, eds. The English Language in Singapore: Research on Pronunciation. Singapore: Singapore Association for Applied Linguistics, 65-75. 
Przedlacka, Joanna. 2002. Estuary English? Frankfurt am Main: Peter Lang.

Przedlacka, Joanna. 2005. "Models and myth”. In Katarzyna Dziubalska-Kołacyk and Joanna Przedlacka, eds. English Pronunciation Models: A Changing Scene. Bern: Peter Lang, 17-36.

Salbrina binti Haji Sharbawi. 2006. "The vowels of Brunei English: an acoustic investigation”. English World-Wide 27: 247-64.

Schneider, Edgar W. 2003. "The dynamics of New Englishes: from identity construction to dialect birth". Language 79: 233-81.

Schneider, Edgar W. 2007. Postcolonial Englishes: Varieties Around the World. Cambridge: Cambridge University Press.

Setter, Jane. 2003. “A comparison of speech rhythm in British and Hong Kong English". Proceedings of the 15th International Congress of Phonetic Sciences. Barcelona, August 2003: 467-70.

Setter, Jane and David Deterding. 2003. "Extra final consonants in the English of Hong Kong and Singapore". Proceedings of the 15th International Congress of Phonetic Sciences. Barcelona, August 2003, 1875-8.

Stibbard, Richard. 2004. "The spoken English of Hong Kong: A study of co-occurring segmental errors”. Language, Culture and Curriculum 17: 127-42. 
Tan Kah Keong. 2005. "Vocalisation of /1/ in Singapore English". In David Deterding, Adam Brown and Low Ee Ling, eds. English in Singapore: Phonetic Research on a Corpus, Singapore: McGraw-Hill, 43-53.

Tong, Keith S. T. and Gregory James. 1994. Colloquial Cantonese. London: Routledge.

van Bergem, Dick. 1995. "Perceptual and acoustic aspects of lexical vowel reduction, a sound change in progress". Speech Communication 16: 329-58.

Wee, Lionel. 2004. “Singapore English: Phonology”. In Edgar W. Schneider, Kate Burridge, Bernd Kortmann, Rajend Mesthrie and Clive Upton eds. A Handbook of Varieties of English. Volume 1: Phonology. Berlin: Mouton de Gruyter, 1017-33.

Wells, John. 1982. Accents of English. Cambridge: Cambridge University Press.

Wong, Cathy Sin Ping and Jane Setter. 2002. "Is it "night" or "light"? How and why Cantonese-speaking ESL learners confuse syllable-initial [n] and [1]" In Allan James and Jonathan Leather, eds. New Sounds 2000: Proceedings of the Fourth International Symposium on the Acquisition of Second Language Speech, University of Klagenfurt, Austria, 351-9.

Zee, Eric. 1999. "Chinese (Hong Kong Cantonese)". In IPA ed. Handbook of the International Phonetic Association. Cambridge: Cambridge University Press, $58-60$. 
Zee, Eric and Wai-Sum Lee. 2007. "Vowel typology in Chinese". Proceedings of the

16th International Congress of Phonetic Sciences, Saarbrücken, 6-10 August 2007, $1429-33$. 
Figure 1. Monophthong vowels of Hong Kong English

F2 (Bark)

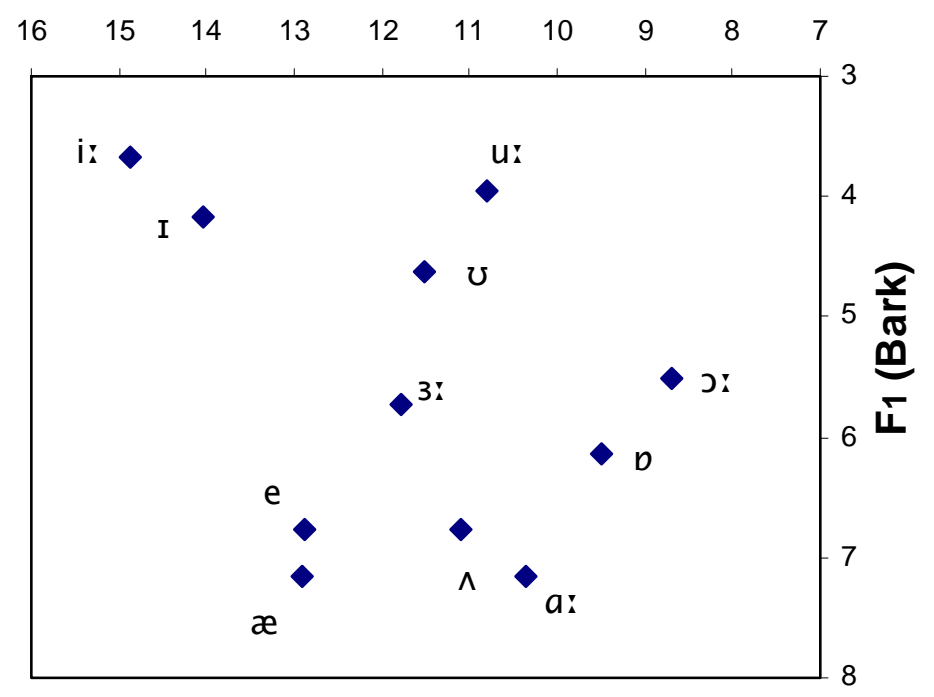


Figure 2. Monophthong vowels of Singapore English (from Deterding (2003))

\section{F2 (Bark)}

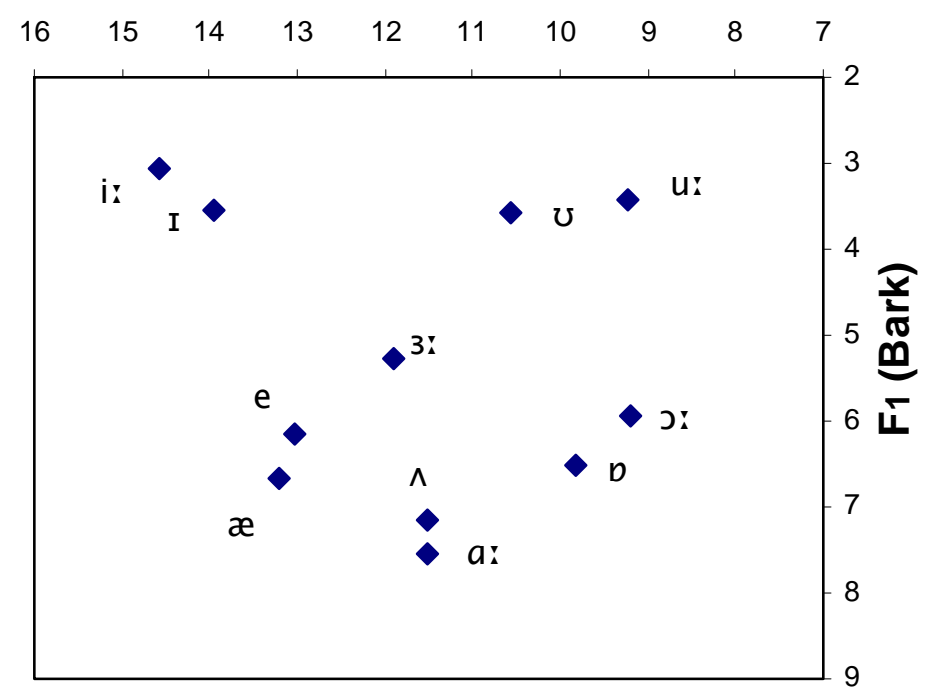


Figure 3. Formant Trajectories of FACE and GOAT

\section{F2 (Bark)}

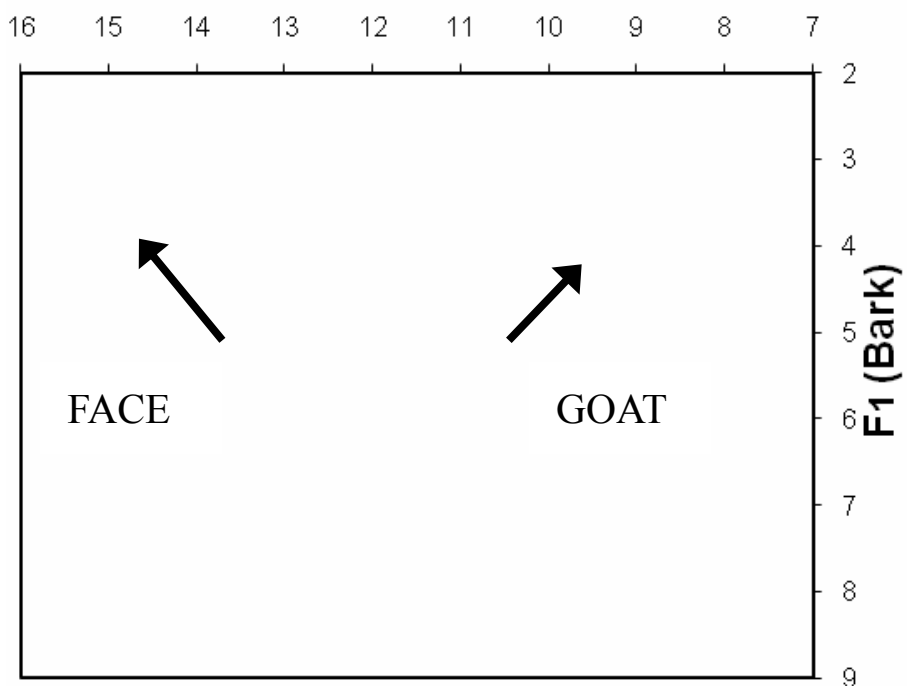


Table 1. Brief details about the speakers and the interviews.

\begin{tabular}{|c|c|c|c|c|c|}
\hline Speaker & Age & Second & Third & Duration of & Number of Words \\
\hline & & Language & Language & Interview (Sec) & by Interviewee \\
\hline F1 & 23 & English & & 193 & 365 \\
\hline $\mathrm{F} 2$ & 23 & English & & 106 & 228 \\
\hline F3 & 23 & English & Mandarin & 193 & 431 \\
\hline F4 & 23 & Mandarin/English & & 177 & 227 \\
\hline F5 & 23 & English & Mandarin & 134 & 219 \\
\hline F6 & 22 & English & Mandarin & 116 & 169 \\
\hline F7 & 24 & English & Mandarin & 92 & 117 \\
\hline F8 & 22 & English & Mandarin & 177 & 320 \\
\hline F9 & 22 & Mandarin & English & 142 & 200 \\
\hline F10 & 22 & English & Mandarin & 202 & 329 \\
\hline F11 & 22 & English & Mandarin & 189 & 360 \\
\hline F12 & 23 & English & & 198 & 386 \\
\hline F13 & 23 & English & Mandarin & 110 & 151 \\
\hline F14 & 22 & English & Mandarin & 155 & 362 \\
\hline F15 & 22 & English & Mandarin & 219 & 464 \\
\hline
\end{tabular}


Table 2. Pronunciation of voiceless TH in initial position.

\begin{tabular}{|c|c|c|c|}
\hline \multirow{2}{*}{ Word } & \multicolumn{3}{|c|}{ Pronounciation of TH } \\
\hline think & 18 & 7 & {$[\mathrm{t}]$} \\
\hline three & 2 & 5 & 1 \\
\hline theme(s) & 4 & 1 & \\
\hline thing & 2 & & \\
\hline thirteen & & 1 & \\
\hline thank & 1 & & \\
\hline total & 27 & 14 & \\
\hline
\end{tabular}


Table 3. Pronunciation of voiceless TH in medial position.

\begin{tabular}{|c|c|c|c|c|}
\hline \multirow{2}{*}{ Word } & \multicolumn{4}{|c|}{ Pronunciation of TH } \\
\hline & {$[\theta]$} & {$[\mathrm{f}]$} & {$[\mathrm{t}]$} & zero \\
\hline something & 4 & & 2 & 2 \\
\hline everything & 1 & & & \\
\hline methods & 1 & & & 2 \\
\hline total & 6 & 0 & 2 & \\
\hline
\end{tabular}


Table 4. Pronunciation of voiceless TH in final position.

\begin{tabular}{|c|c|c|c|c|}
\hline \multirow{2}{*}{ Word } & \multicolumn{4}{|c|}{ Pronunciation of TH } \\
\hline youth & {$[\theta]$} & {$[\mathrm{f}]$} & {$[\mathrm{t}]$} & zero \\
\hline both & & 4 & & \\
\hline fourth & 1 & 2 & & \\
\hline month & 1 & & & 1 \\
\hline months & & & & 1 \\
\hline total & 2 & 6 & & \\
\hline
\end{tabular}


Table 5. Realisation of voiceless $\mathrm{TH}$ according to speaker

\begin{tabular}{|c|c|c|c|c|}
\hline Speaker & {$[\theta]$} & {$[\mathrm{f}]$} & {$[\mathrm{t}]$} & zero \\
\hline F1 & & 6 & & \\
\hline F2 & 4 & & & \\
\hline F3 & 7 & 1 & 2 & \\
\hline F4 & & 1 & & \\
\hline F5 & 4 & 2 & & 1 \\
\hline F6 & 3 & & & \\
\hline F7 & 1 & & & \\
\hline F8 & 2 & & & \\
\hline F9 & & 2 & & 1 \\
\hline F10 & 1 & 6 & & 1 \\
\hline F11 & 2 & 2 & & \\
\hline F12 & & & 1 & \\
\hline F13 & 2 & & & \\
\hline F14 & 2 & & & \\
\hline F15 & 7 & & & \\
\hline
\end{tabular}


Table 6. Deletion of final plosives from word-final consonant clusters before a pause or vowel.

\begin{tabular}{|c|c|c|c|}
\hline Plosive & Retained & Deleted & Per Cent Deleted \\
\hline$[\mathrm{t}]$ & 19 & 17 & $47.2 \%$ \\
\hline$[\mathrm{d}]$ & 6 & 10 & $62.5 \%$ \\
\hline$[\mathrm{k}]$ & 7 & 10 & $58.8 \%$ \\
\hline Total & 32 & 37 & $53.6 \%$ \\
\hline
\end{tabular}


Table 7. Rate of Change (Hz per sec) for Hong Kong English, Singapore English and British English.

\begin{tabular}{|l|c|c|c|}
\hline & Hong Kong & Singapore & RP British English \\
& & (from Deterding 2000) & (from Deterding 2000) \\
\hline FACE & -1121 & -388 & -1378 \\
\hline GOAT & -909 & -266 & -1301 \\
\hline
\end{tabular}


Table 8. Incidence of full and reduced vowels in the unstressed first syllable of polysyllabic words with 'a', 'o' and 'u' in the spelling.

\begin{tabular}{|l|l|l|}
\hline letter & full vowel & reduced vowel \\
\hline & $\begin{array}{l}\text { accept, alumni, applied, } \\
\text { association, attraction, } \\
\text { cannot, magician, patrol, }\end{array}$ & allowed, amazing, another (2), \\
& $\begin{array}{l}\text { statistics, traditional } \\
\text { a }\end{array}$ & assessment, assignments, assistant, \\
\hline o & communicate, comparing, considerate, & attraction, balloon, facilities, \\
& collection, commercial, computers, \\
& horizons, producers, producing, & Macao, materials, particular, \\
& forgot (2), proficient \\
\hline
\end{tabular}


Table 9. Vowel quality in function words.

\begin{tabular}{|l|c|c|}
\hline word & full vowel & reduced vowel \\
\hline and & 39 & 3 \\
\hline as & 4 & 0 \\
\hline at & 2 & 0 \\
\hline but & 3 & 2 \\
\hline for & 14 & 5 \\
\hline from & 1 & 7 \\
\hline of & 13 & 5 \\
\hline that & 3 & 7 \\
\hline to & 24 & 5 \\
\hline was & 15 & 5 \\
\hline total & 118 & 5 \\
\hline
\end{tabular}

